\title{
Revised Equation of State for FLiBe in MELCOR
}

Paul W. Humrickhouse and Brad J. Merrill

December 2017

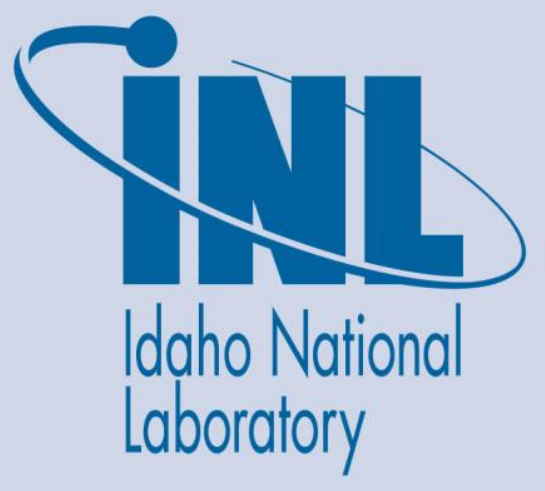

The INL is a U.S. Department of Energy National Laboratory operated by Battelle Energy Alliance 


\section{DISCLAIMER}

This information was prepared as an account of work sponsored by an agency of the U.S. Government. Neither the U.S. Government nor any agency thereof, nor any of their employees, makes any warranty, expressed or implied, or assumes any legal liability or responsibility for the accuracy, completeness, or usefulness, of any information, apparatus, product, or process disclosed, or represents that its use would not infringe privately owned rights. References herein to any specific commercial product, process, or service by trade name, trade mark, manufacturer, or otherwise, does not necessarily constitute or imply its endorsement, recommendation, or favoring by the U.S. Government or any agency thereof. The views and opinions of authors expressed herein do not necessarily state or reflect those of the U.S. Government or any agency thereof. 


\title{
Revised Equation of State for FLiBe in MELCOR
}

\author{
Paul W. Humrickhouse and Brad J. Merrill
}

December 2017

\begin{abstract}
Idaho National Laboratory
Fusion Safety Program

Idaho Falls, Idaho 83415
\end{abstract}

http://www.inl.gov

Prepared for the

U.S. Department of Energy

Office of Science

Under DOE Idaho Operations Office

Contract DE-AC07-05ID14517 


\begin{abstract}
The equation of state from which thermodynamic properties of FLiBe are derived in MELCOR for Fusion has been revised. The primary purpose of the revision was to ensure that the saturation pressure derived from the equation of state (via the Maxwell construction) is consistent with measured values; a large discrepancy existed in the prior equation. The form of the new equation and its parameters, which were adjusted to fit experimental data, are given here. It is shown that the new equation reproduces density, specific heat, sound speed, and vapor pressure data more accurately than previously.
\end{abstract}




\section{CONTENTS}

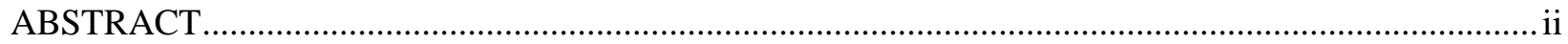

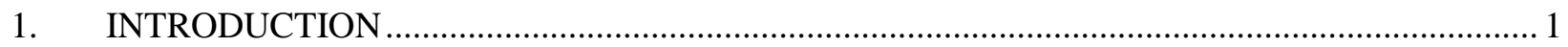

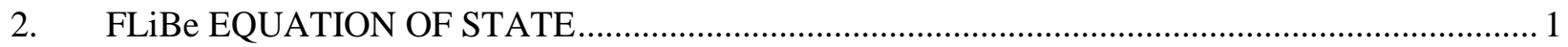

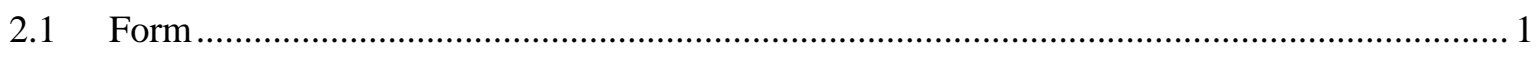

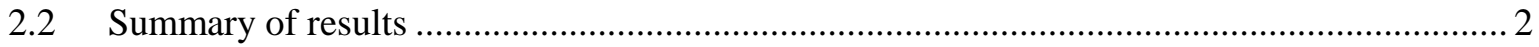

\section{FIGURES}

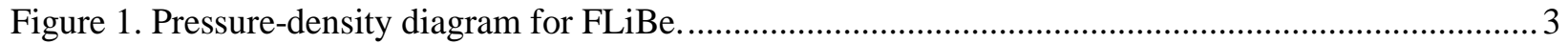

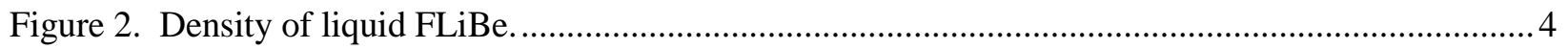

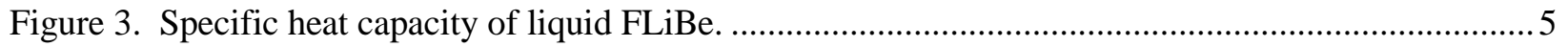

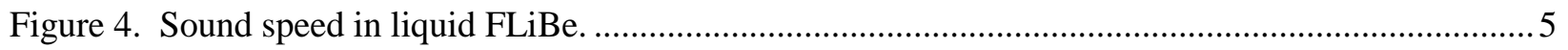

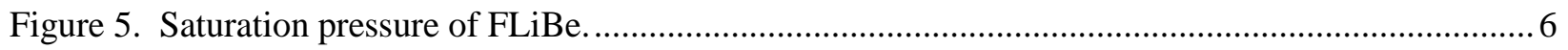

\section{TABLES}

Table 1. Fit parameters for the FLiBe equation of state. 


\section{Revised Equation of State for FLiBe in MELCOR}

\section{INTRODUCTION}

This work is a part of an on-going effort to revise the alternate fluid property data files originally developed by the INL Fusion Safety Program for the ATHENA code, and now used in both RELAP5-3D and MELCOR for Fusion. The objectives of this effort are to:

- Improve the accuracy of the data files compared to new measured or existing reference data;

- Ensure vapor pressures predicted by the equations of state are consistent with empirical values;

- Produce property tables with a finer resolution for improved calculation accuracy;

- Eliminate code execution errors resulting from deficiencies in one or more of the above, or other issues.

The present FLiBe property file ("tpffi") is an implementation by Moore [1] of the FLiBe equation of state developed by Chen et al. [2], which was fitted to density, enthalpy and sound speed data. It did not take any vapor pressure data into consideration; in the existing implementation, as with all the other ATHENA fluids, saturation properties were determined by finding the intersection of the equation of state with an empirical vapor pressure curve. But the equation of state itself implies a particular vapor pressure curve, obtainable via by the Maxwell construction (equal area rule), which ensures mechanical, thermal, and chemical equilibrium between the coexistent phases. We found that the vapor pressures computed from Chen's equation of state were many orders of magnitude lower than the established empirical values, and so have fitted a generalized form that gives approximately correct vapor pressure values while maintaining close agreement with other thermodynamic properties.

\section{FLIBe EQUATION OF STATE}

\subsection{Form}

Chen's equation of state is of the "soft-sphere" form [3], which has five fit parameters, but a sixth is added by allowing the leading coefficient of the $\ln (T)$ term to vary. It was shown in [4] that the soft sphere equation of state is a special case of a widely-used form of the Helmholtz free energy used to develop highly accurate reference equations of state [5], which, after some simplification suitable for present purposes, can be written as:

$$
\frac{a}{R_{S} T}=s_{0}+u_{0}\left(\frac{T_{m}}{T}\right)+\ln \left(\frac{\rho}{\rho_{m}}\left(\frac{T_{m}}{T}\right)^{C_{0}}\right)+\sum_{i=1}^{5} n_{i}\left(\frac{T_{m}}{T}\right)^{t_{i}}\left(\frac{\rho}{\rho_{m}}\right)^{d_{i}}
$$

Here $a$ is the specific Helmholtz free energy, with units of energy per unit mass; $R_{s}$ is the specific gas constant (84.078 J/kg-K for FLiBe); $T$ and $\rho$ are the temperature and density; $T_{m}$ and $\rho_{m}$ are the temperature and density at the melting point $\left(732.3 \mathrm{~K}\right.$ and $1991.6 \mathrm{~kg} / \mathrm{m}^{3}$ for $\left.\mathrm{FLiBe}\right)$; and $s_{0}, u_{0}, c_{0}, n_{i}, t_{i}$, and $d_{i}$ are dimensionless fit parameters. 
All other thermodynamic properties can be derived from the above fundamental relation. Pressure and entropy functions are determined by taking:

$$
\begin{aligned}
& P=-\left(\frac{\partial a}{\partial v}\right)_{T} \\
& S=-\left(\frac{\partial a}{\partial T}\right)_{v}
\end{aligned}
$$

where the specific volume $v=1 / \rho$. Liquid density is calculated by finding the three roots of Equation 2 at a given pressure; the largest density corresponds to the liquid value. The specific heat capacity $c_{p}$ and sound speed $w$, which along with density are used to fit the equation, are given by:

$$
\begin{gathered}
c_{p}=T\left(\frac{\partial s}{\partial T}\right)_{P}=T\left[\left(\frac{\partial s}{\partial T}\right)_{v}-\left(\left(\frac{\partial P}{\partial T}\right)_{v}^{2} /\left(\frac{\partial P}{\partial v}\right)_{T}\right)\right] \\
w=\sqrt{\left(\frac{\partial P}{\partial \rho}\right)_{S}}=v \sqrt{\left(\left(\frac{\partial P}{\partial T}\right)_{v}^{2} /\left(\frac{\partial S}{\partial T}\right)_{v}\right)-\left(\frac{\partial P}{\partial v}\right)_{T}} .
\end{gathered}
$$

Finally, the saturation pressure is determined by solving the system

$$
\begin{gathered}
P_{\text {sat }}=P\left(v_{\ell}, T_{\text {sat }}\right) \\
P_{\text {sat }}=P\left(v_{v}, T_{\text {sat }}\right) \\
P_{\text {sat }}\left(v_{\ell}-v_{v}\right)=a\left(v_{v}, T_{\text {sat }}\right)-a\left(v_{\ell}, T_{\text {sat }}\right)
\end{gathered}
$$

for $P_{s a t}, v_{\ell}$, and $v_{v}$, the specific volumes of the liquid and vapor, respectively.

\subsection{Summary of results}

The fit parameters $s_{0}, u_{0}, c_{0}, n_{i}, t_{i}$, and $d_{i}$ are determined by fitting the density, specific heat, sound speed, and vapor pressure, determined from the fundamental relation as described above, to experimental data via the methods described in [4]. The resultant parameters for FLiBe are given in Table 1. A pressure-density plot, showing isotherms through the predicted multiphase region and up to the critical point, is shown in Figure 1. The predicted critical point occurs at:

$$
\begin{aligned}
T_{c} & =3416.87 \mathrm{~K} \\
P_{c} & =83.94 \mathrm{MPa} \\
\rho_{c} & =556.33 \mathrm{~kg} / \mathrm{m}^{3} .
\end{aligned}
$$


Table 1. Fit parameters for the FLiBe equation of state.

\begin{tabular}{|c|c|c|c|c|c|c|}
\hline$i$ & $n_{i}$ & $t_{i}$ & $d_{i}$ & $s_{0}$ & $u_{0}$ & $c_{0}$ \\
\hline 1 & 0.9307 & 0.9599 & 0 & \multirow{5}{*}{4.466} & \multirow{5}{*}{-15.34} & \multirow{5}{*}{19.12} \\
\hline 2 & 36.62 & 0.9663 & 0 & & & \\
\hline 3 & 45.17 & 1.014 & 3.151 & & & \\
\hline 4 & 32.29 & 0.4468 & 1.924 & & & \\
\hline 5 & -104.1 & 0.9629 & 1.998 & & & \\
\hline
\end{tabular}

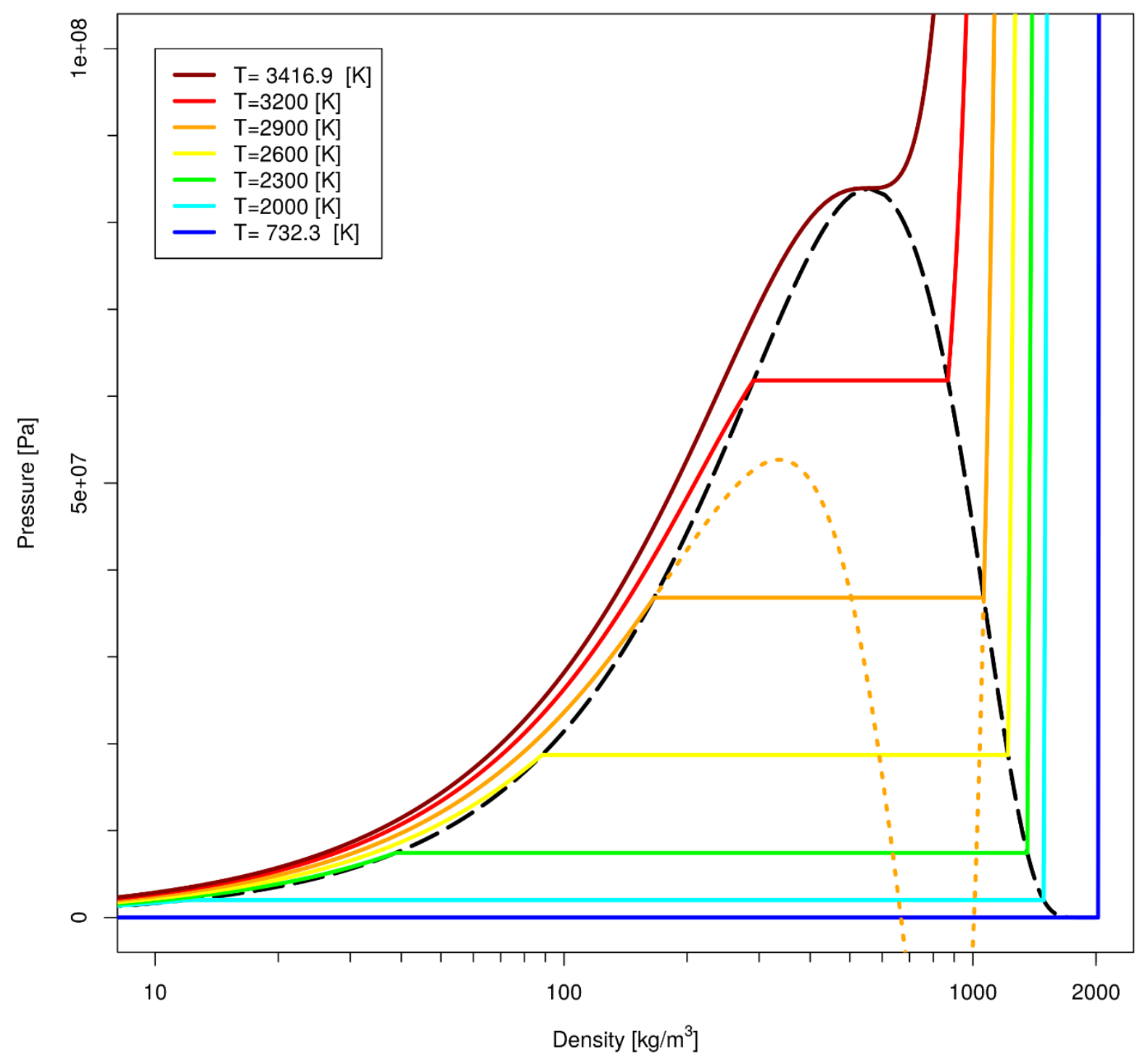

Figure 1. Pressure-density diagram for FLiBe. 
This is of only academic interest, since it is determined by extrapolating far beyond the range of experimental data, and therefore may not be close to the actual critical point, which is not known.

The equation of state predictions (using the parameters in Table 1) are compared to those of the previous equation of state [2] and the experimental values [6] (to which the former are fitted) in Figures 2-5. It is clear that the new equation of state reproduces with high accuracy the experimental values for density and sound speed. The specific heat of FLiBe is said to be independent of temperature, and the new equation of state reproduces this more accurately than the previous one. The improvement is particularly evident in the saturation pressure, which was a primary objective of this work. The fitting is complicated here by the absence of any vapor phase data and is therefore inexact, but the saturation pressure matches the experimental values reasonably well throughout the range of practical interest.

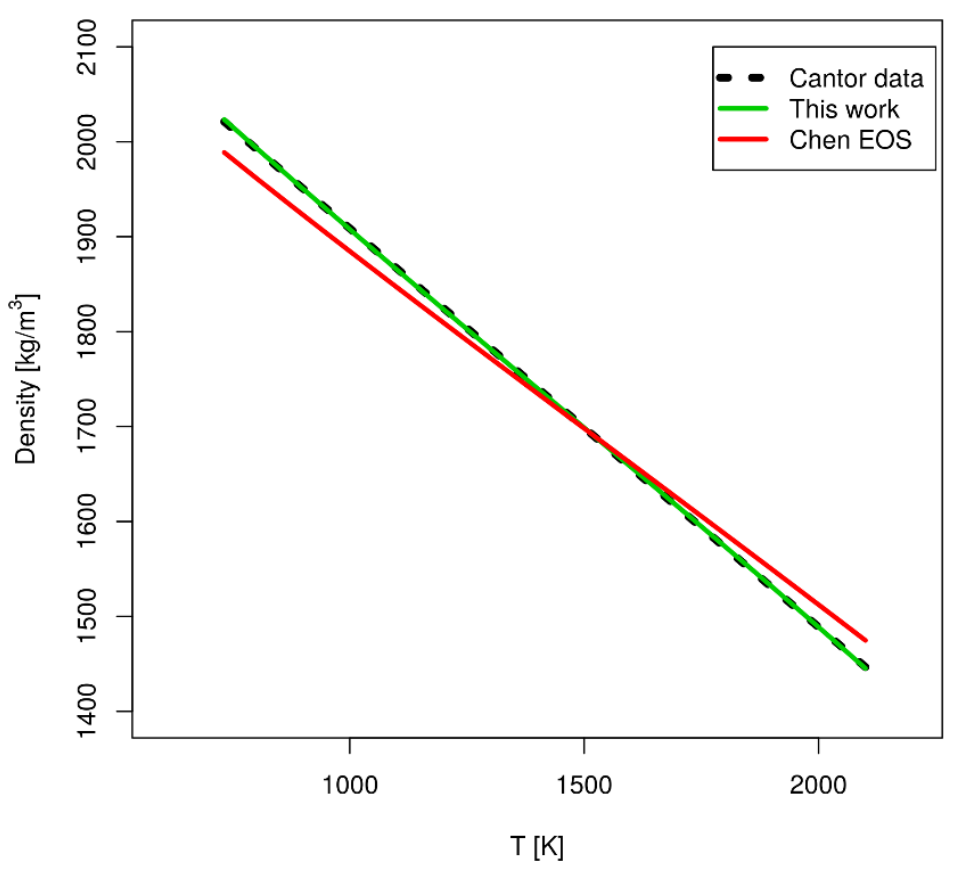

Figure 2. Density of liquid FLiBe. 


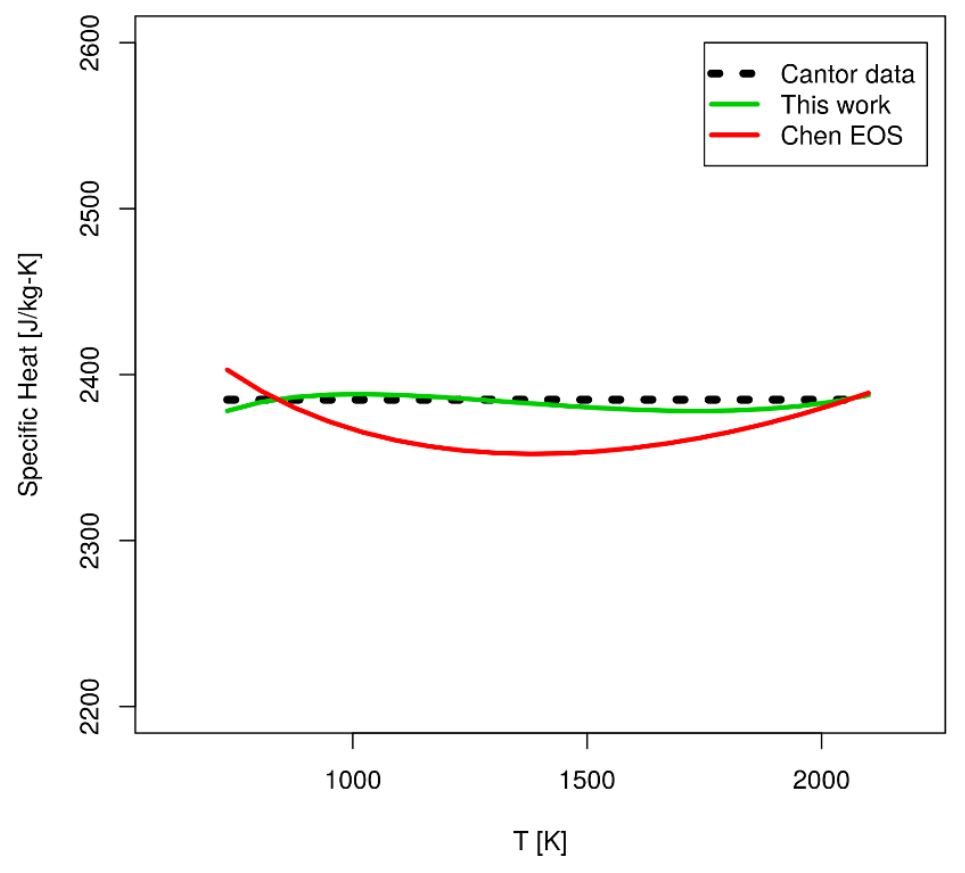

Figure 3. Specific heat capacity of liquid FLiBe.

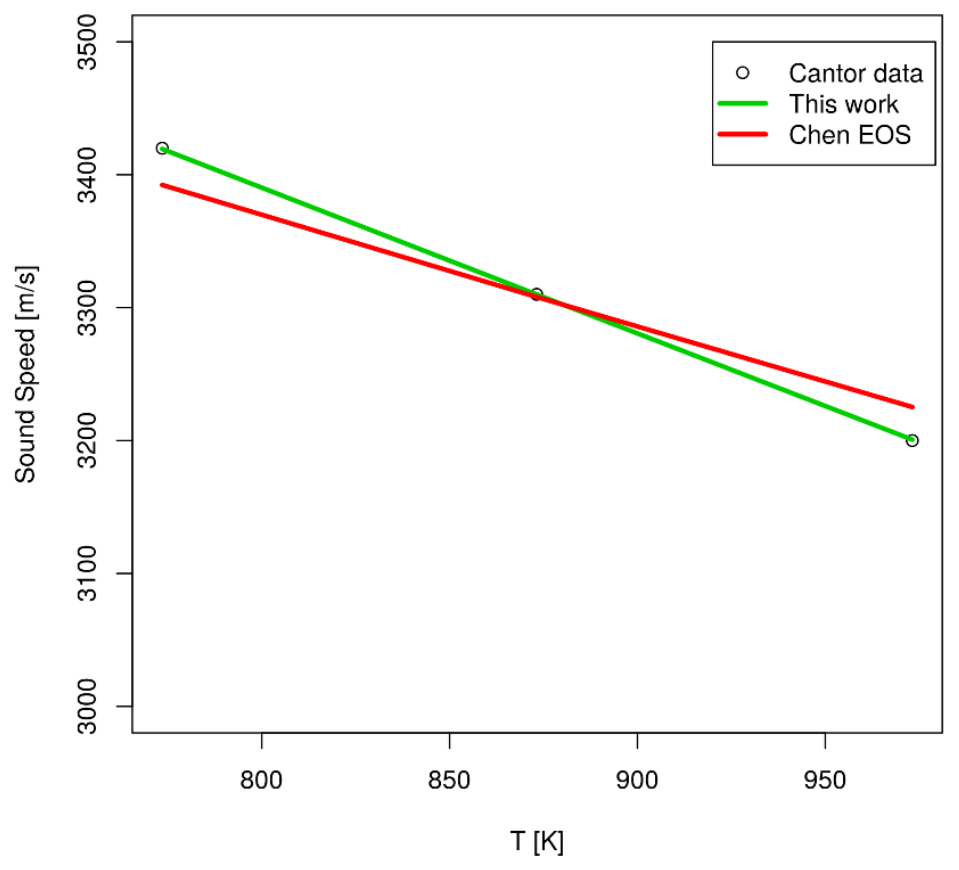

Figure 4. Sound speed in liquid FLiBe. 


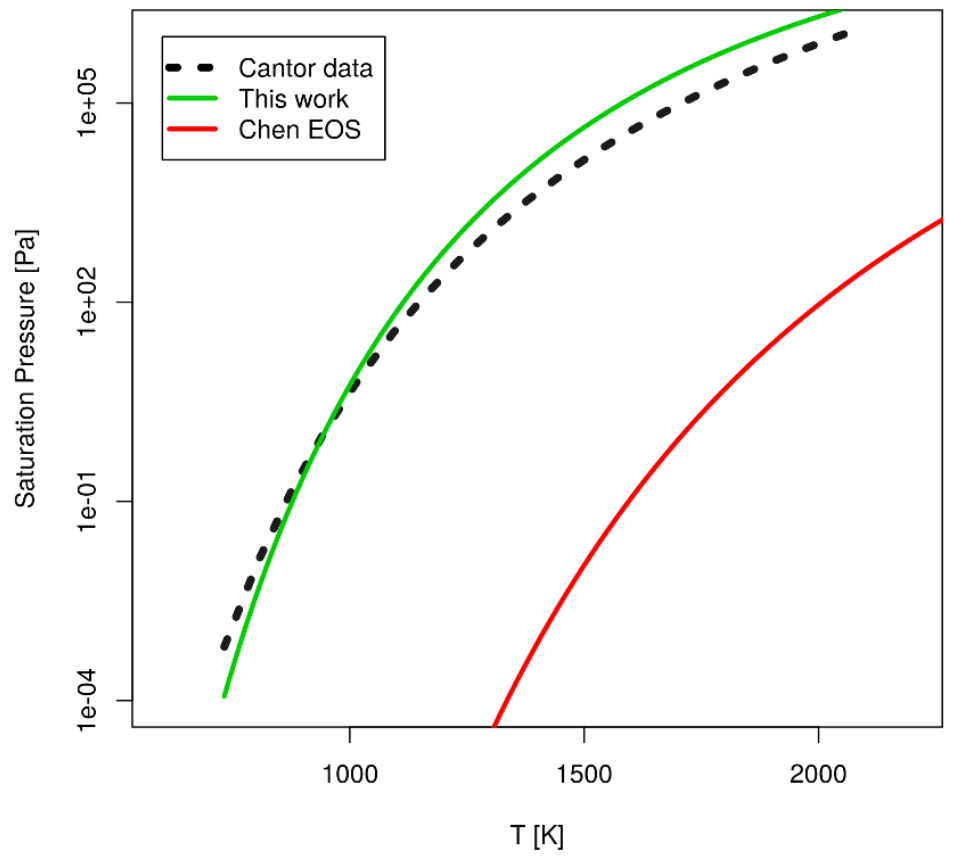

Figure 5. Saturation pressure of FLiBe. 


\section{REFERENCES}

1. R. L. Moore, "Flibe Thermal Properties for use with the Fusion Safety Multi-fluid Equation of State Package," INEEL/EXT-2000-00670, Idaho National Laboratory, May 2000.

2. X. M. Chen, V. E. Schrock, and P. F. Peterson, "The Soft-Sphere Equation of State for Liquid Flibe," Fusion Technology 21 (1992) 1525-1530.

3. D. A. Young, "A Soft-Sphere Model for Liquid Metals," UCRL-52352, Lawrence Livermore National Laboratory, 1977.

4. P. W. Humrickhouse and B. J. Merrill, "An Equation of State for Liquid $\mathrm{Pb}_{83} \mathrm{Li}_{17}$," Fusion Engineering and Design (2017), in press.

5. R. Span, Multiparameter Equations of State, Springer, Berlin, 2000.

6. S. Cantor (Ed.), "Physical Properties of Molten-Salt Reactor Fuel, Coolant, and Flush Salts," ORNL-TM-2316, Oak Ridge National Laboratory, August 1968. 